\title{
Gehasste Pioniere
}

Erhard Taverna
Was haben Sigmund Freud, Wilhelm Reich, Magnus Hirschfeld und Alfred Charles Kinsey, drei Mediziner und ein Wespenforscher, gemeinsam? Sie wurden gehasst, verleumdet und angegriffen, weil ihre Erkenntnisse die Machtmechanismen der etablierten Sozialkontrolleure blosslegten. Freud überlebte dank Intervention des britischen Königshauses, Reich geriet am Ende seines Exils in die Fänge der CIA, Hirschfeld wurde zusammengeschlagen und flüchtete nach Frankreich, Kinsey wurde durch eine jahrelange Hexenjagd in den frühen Herzinfarkt getrieben. Wenig deutet darauf hin, dass es ihnen heute viel besser ergehen würde.

Magnus Hirschfeld (1868-1935) war der Begründer der Sexualwissenschaft, ein zu Unrecht vergessener Pionier, dessen Gedanken, dank einer Publikation des Eichborn Verlages, 70 Jahre später, wieder zugänglich sind. Das Buch «Weltreise eines Sexualforschers» ist eine lohnende Lektüre, weil es die Geschichte eines aussergewöhnlich klugen und warmherzigen Menschen erzählt. Hirschfeld war weder ein genialer Entdecker wie Freud noch ein verstiegener Visionär wie Reich. In besseren Zeiten hätte er vielleicht die Breitenwirkung der Kinsey-Reports vorweggenommen. Ein langjähriger Mitarbeiter schilderte ihn als «Realist, Tatsachenkopf, Mann der direkten Methode, Deskriptor, Empiriker. Kein Seher, ein Aufklärer, ein unermüdlicher und erfolgreicher Sammler, Beschreiber und Ordner von Tatsachen, auf die bis dahin der Blick gemeinhin nicht fiel ...».

Seine Reise begann 1931 mit einer Einladung der deutsch-amerikanischen Ärzteschaft, einen Vortrag «Über den gegenwärtigen Stand der Sexualpathologie» zu halten. Damit begann eine Vortragstournee um die ganze Welt, von den USA nach Japan und China, nach Indonesien, Indien und den nahen Osten. Im Vorwort seines ausführlichen Berichtes nennt er sich einen Ethnologen, einen völkerkundlichen Sexualforscher, der sich aufmacht, die Geschlechtsund Liebessitten der verschiedenen Völker, Länder und Zeiten auszumachen. Für ihn steht an erster Stelle seiner Studien die «Stellung der Frau zum Mann», was ihn bereits von den meisten Zeitgenossen abhebt. Als zweiten Gegenstand nennt er die Ehesitten, als drittes die Familien- und Sippenbildungen, als viertes die Familienplanung, weiter Körper- und Genital-

\section{Résumé}

Les grands chercheurs en sexualité ont toujours subi la haine des apôtres de la morale publique. Pionnier oublié et féministe avant la lettre, Magnus Hirschfeld, mort à Nice en 1935, a décrit un monde bizarre dans son ouvrage «Voyage autour du Monde».

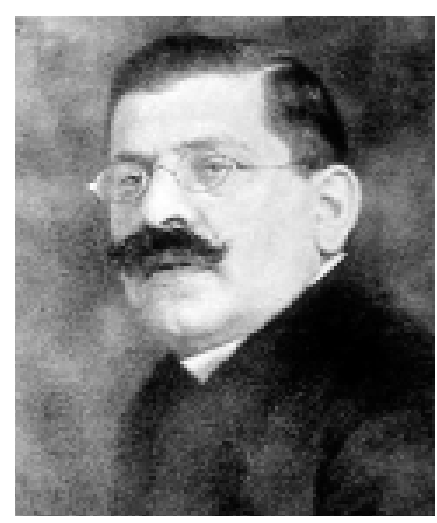

Ausgezeichneter und vorurteilsloser Beobachter: Magnus Hirschfeld (1868-1935).

veränderungen, Kleidersitten, Berührungsrituale, Erziehung, Religion und Prostitution.

Hirschfeld ist ein ausgezeichneter und vor allem ein vorurteilsloser Beobachter, frei von eurozentrischem Rassendünkel und männlichen Überlegenheitsfantasien. Er ist offen und neugierig, aber auch immer, bei aller Distanz des Professors, mit Brille, Schnauz und Fliege, ein mitfühlender und unbestechlicher Beobachter sozialen Lebens, der Gewalt und Unrecht, ohne Rücksicht auf seine Gastgeber, beim Namen nennt. Das Resultat seiner Feldforschung fasst er kurz zusammen: Anlagen und Triebe sind überall gleich, es gibt nur individuelle Unterschiede. Es gibt keine «niedrigen» Kulturstufen. Der Ursprung der Geschlechtssitten ist überall realer Natur, alle symbolistischen und idealistischen Erklärungen sind nachträgliche Konstruktionen. Alle halten sich für objektiv sittlich und verwerfen andere Bräuche als unsittlich. Für die Verwirklichung der sexuellen Menschenrechte braucht es eine wissenschaftliche Menschen- und Geschlechtskunde. 
Geworden ist ein anrührendes, schönes und trauriges Zeitdokument, eine Momentaufnahme der letzten Jahre vor der vermeidbaren Katastrophe des zweiten Weltkrieges. Ein farbenfroher Bericht über Länder und Leute, ein Protokoll der Illusionen und Hoffnungen von Forschern, Politikern, Männern und Frauen aller Gesellschaftsschichten. Vieles wird prophetisch vorweggenommen, etwa Japans imperiale Versuchung, die Vitalität Chinas, das Scheitern der westlichen Kolonien oder das Konfliktpotential im nahen Osten. Was er als Dilemma in Palästina schildert, lange vor der Gründung des Staates Israel, entspricht bis in alle Details den heutigen Lageanalysen. Hirschfeld arbeitete in Deutschland mit Umfrageerhebungen in der Bevölkerung, wie eine Generation später Kinsey in den USA. Er war rastlos tätig, auf Vortragsreisen, als Spezialarzt und Herausgeber wissenschaftlicher und pädagogischer Werke, als Gründer eines Institutes in Berlin, der ärztlichen Gesellschaft für Sexualwissenschaft und Eugenik, der Weltliga für Sexualreform und als Mitarbeiter von aufklärenden Filmen.

Hirschfeld wird 1920 in München von Nazischlägern krankenhausreif zusammengeschlagen, das Institut 1933, wenige Monate nach der Publikation seiner Weltreise, zerstört und seine Schriften verbrannt. Und noch eine Fussnote: $\mathrm{Ob}$ in New York oder Yokohama, Nanking oder Kairo, überall gibt es ein einheimisches, interessiertes Publikum, das seine deutsch vorgetragenen Ausführungen versteht. Hirschfeld stirbt 1935 in Nizza. Ein Jahrzehnt später ist auch eine Sprachweltkultur unwiderruflich verspielt.

Magnus Hirschfeld, Weltreise eines Sexualforschers im Jahre 1931/32,

Eichborn Verlag Frankfurt am Main 2006, die andere Bibliothek, 444 Seiten. Magnus-Hirschfeld-Gesellschaft, www.hirschfeld.in-berlin.de 